\title{
Artículos
}

\section{Lógicas de inserción del urbanismo residencial cerrado al sur de Tamaulipas}

\section{Logics of insertion of the closed residential urbanism in southern Tamaulipas}

\author{
Judith del Carmen Garcés Carrillo* \\ Mireya Alicia Rosas Lusett**
}

\begin{abstract}
Resumen
El presente artículo comprende el análisis de las lógicas de inserción del nuevo urbanismo residencial cerrado, contenido en fragmentos dispersos sobre la periferia y emplazados dentro de las retículas urbanas en el sistema de ciudades que conforman Tampico, Ciudad Madero y Altamira, al sur del estado de Tamaulipas, México. Para tal fin se utilizan las variables de localización del lugar, las características del entorno espacial, su dimensión y morfología, debido a que su incidencia de localización interviene en la formación de la periferia y la fragmentación urbana que prevalecen hoy en día.
\end{abstract}

Palabras clave: urbanismo residencial cerrado; tendencias de localización.

\begin{abstract}
The present article includes the analysis of the logics of insertion of the new closed residential urbanism contained in dispersed fragments on the periphery, and located within the urban reticles in the system of cities conformed by Tampico, Ciudad Madero and Altamira to the south of the state of Tamaulipas, Mexico. For this purpose, the main variables used were localization of the place, the characteristics

* Profesora investigadora de la Universidad Autónoma de Tamaulipas, Facultad de Arquitectura, Diseño y Urbanismo. Dirección postal: Centro Universitario s/n, Universidad Sur, 89000 Tampico, Tamps., México. Correo electrónico: jgarces@uat.edu.mx y arqjudithgarces@ gmail.com

** Profesora investigadora de la Universidad Autónoma de Tamaulipas, Facultad de Arquitectura, Diseño y Urbanismo. Dirección postal: Centro Universitario s/n, Universidad Sur, 89000, Tampico, Tamps., México. Correo electrónico: mire.rosas@gmail.com
\end{abstract}


of the spatial environment and its dimension and morphology, because the location incidence intervenes in the formation of the periphery and the urban fragmentation that prevails today.

Keywords: closed residential urbanism; location trends.

\section{Introducción}

La intromisión del capital financiero trasnacional en el mercado inmobiliario, la globalización económica y la política del neoliberalismo en México, impulsaron a la sociedad a demandar transformaciones en las formas urbanas ya establecidas, debido principalmente a la intervención de factores colaterales, tales como el incremento del desempleo, la agudización de la pobreza, la desigualdad, la exclusión, la violencia y la inseguridad en las ciudades; cambiando con esto las necesidades y expectativas de ciertos grupos de la sociedad, quienes se sienten vulnerables y amenazados tras imponerse un nuevo estilo de vida y un nuevo orden en la organización de la ciudad, e irrumpiendo el concepto de urbanismo cerrado. En palabras de Vidal-Koppmann (2014, p. 45), los procesos de globalización y mundialización "estarían diseñando nuevas geografías", en donde la conformación de cada fragmento urbano "obedece a su propia lógica, sin que vislumbre una visión de todo el sistema en conjunto" (Vidal-Koppmann, 2014, p. 170).

Esta misma crisis acrecentó las discrepancias entre la población, convirtiéndose en otro de los factores que han definido el auge del urbanismo cerrado, resultando difícil negar la hipótesis acerca de que la proliferación del fenómeno del urbanismo residencial cerrado sea resultado de la más reforzada polarización social, produciendo, según Castells (1999), "la morfología de la nueva ciudad contemporánea".

Se menciona que en México el concepto del encierro urbano se habría infiltrado con anterioridad a los acontecimientos antes descritos, pero bajo conceptos e ideales distintos a los concebidos en el modelo norteamericano de los gated communities o barrios cerrados donde prevalece el ideal de los jardines comunitarios y la idea de compartir ciertas áreas del fragmento entre los vecinos de la comunidad, una especie de remembranza de las ciudades jardín de 1898 diseñadas por Ebenezer Howard. Sin embargo, la sola idea de compartir las propiedades no fue la mejor opción y tampoco se percibió como un ideal, debido a que los mexicanos consideraron que "el espacio familiar debe tener un cierto grado de intimidad, por lo que sus límites en las propiedades se materializaron con bardas y rejas" (Giglia, 2001, p. 5, en Juárez-Martínez, 2006, p. 8), de modo que al aumentar la inseguridad 
y el miedo en la ciudad, el encierro urbano se caracterizó por la elevación de dichas murallas macizas o enrejadas, las que perdieron su transparencia con la inclusión de espesas enredaderas vegetales que impiden la visibilidad hacia el interior de las propiedades.

Es importante mencionar que el origen del prototipo del urbanismo cerrado, tal y como se manifiesta hoy en la ciudad contemporánea, no se le atribuye sólo a Estados Unidos. Según Glasze (2003, p. 2), "en la rápida expansión de las metrópolis del siglo XIX en París y Berlín, los inversores privados iniciaron la construcción de viviendas que en su diseño conceptual eran muy similares a muchas de las actuales formas de vecindad privada", de tal manera que las ciudades europeas fueron un referente muy importante para la replicación de las comunidades cerradas norteamericanas y de urbanizaciones cerradas o privadas de otros países del orbe.

A finales del siglo XX, bajo el régimen de condominio, aparecieron los primeros indicios de manifestaciones de este fenómeno ya identificado plenamente como un tipo de urbanismo en forma de fragmentos cerrados residenciales (FCR), muy similar al concepto norteamericano y que proliferó tanto en la Ciudad de México como en las metrópolis de Guadalajara, Puebla, Monterrey y en las de la frontera con Estados Unidos, como Tijuana, Nogales y Ciudad Juárez (Ickx, 2002; Méndez y Rodríguez, 2005), ocupando espacio territorial en particulares localizaciones.

El presente artículo es parte del trabajo de investigación de la tesis doctoral del autor, denominada Incidencia de los fraccionamientos cerrados en la expansión y fragmentación de la Zona Metropolitana de Tampico (2016), en la Universidad Autónoma de Tamaulipas. Tiene como objetivo dar a conocer los resultados de la lógica de inserción de los FCR en la Zona Metropolitana del Sur de Tamaulipas (ZMST), utilizando para este fin las variables de localización y las características del entorno espacial, su dimensión y morfología, debido a que su localización incide en la formación expandida de la periferia y la fragmentación urbana de la zona en general.

\section{Interpretaciones del urbanismo residencial cerrado}

La proliferación del urbanismo cerrado es un fenómeno a nivel global. Esta tendencia se presenta en múltiples ciudades alrededor del mundo de manera simultánea junto con sus particulares características y motivaciones, así como sus distintas denominaciones. En México se le conoce como fraccionamiento cerrado de manera general, pero en algunas ciudades de los estados de Jalisco y de Nayarit se les denomina cotos y claustros residenciales. En la 
ZMST se encuentra asentado en la Ley para el Desarrollo Urbano del Estado de Tamaulipas la denominación fraccionamiento de acceso controlado (Título VIII, Capítulo I, Artículo 49); sin embargo, para efectos de la presente investigación en adelante se le denominará fragmento cerrado residencial (FCR), ya que en esencia sostienen el mismo concepto de urbanización cerrada definido por Roitman (2004, p. 9), quién afirma que:

las urbanizaciones cerradas deben ser consideradas como un área residencial cerrada en donde el espacio público ha sido privatizado por la ley, restringiendo el acceso vehicular o peatonal. De esta forma se privatiza el uso de calles, plazas y parques dentro del perímetro de la urbanización. Estos espacios sólo pueden ser usados por los residentes [...] La urbanización cerrada incluye viviendas unifamiliares de propiedad individual y otros edificios o espacios de uso común que son de propiedad colectiva [...] cuenta con una serie de dispositivos de seguridad, como un cierre perimetral (muro, alambrado o rejas), alarmas, cámaras de circuito cerrado y guardias de seguridad. Generalmente este tipo de urbanización tiene una asociación de residentes con funciones de poder ejecutivo $\mathrm{y}$ en algunas ocasiones legislativo y judicial.

\section{Proliferación del urbanismo cerrado en la ciudad contemporánea}

En los últimos tiempos, la proliferación del urbanismo cerrado tanto en Norteamérica como en América Latina, y particularmente en México, se torna más evidente, generando una significativa producción de investigaciones; entre las más destacadas se encuentran los trabajos de Davis (1999) y Flusty (1994), McKenzie (1994) y Blakely y Snyder (1997) en Estados Unidos; Caldeira (1998), Svampa (2001), Rodríguez y Arriagada (2004), Roitman (2004), Prevot-Shapira (2000), Janoschka (2003), Borsdorf (2003) y Cáceres y Sabatini (2004) en Latinoamérica; así como también Cabrales y Canosa (2001) y Méndez y Rodríguez (2005), en la Ciudad de México y en ciudades fronterizas. Con una perspectiva más amplia están las investigaciones de Webster, Glasze y Frantz (2004), quienes tratan de establecer en el libro Ciudades privadas. Global and local perspective, líneas interpretativas que analizan la dimensión global del fenómeno de la segregación y de las formas de la generación y proliferación del urbanismo cerrado:

a) En Norteamérica el estudio del urbanismo cerrado se centra en los temas sobre la percepción del miedo y la reducción del espacio público, en donde parecen cristalizarse todos los procesos del desarrollo urbano actual de "una ciudad rígidamente estratificada por ocupación y clase, que señala en cambio una vasta difusión del individualismo y la iniciativa de empresa- 
rios, en cuya óptica, posesiones y apariencias son esencialmente las marcas de distinción social" (Harvey, 1990, p. 17).

Davis (1990) y Flusty (1994) coinciden al sostener que la ciudad planeada es una ciudad fría en la que los valores de la comunidad, el esfuerzo individual y las tradiciones están en decadencia, asegurando que este tipo de ciudad produce miedo. Flusty se refiere a la ciudad de Los Ángeles como una urbe que busca la tranquilidad, la seguridad y la disminución de la criminalidad, basándose en la construcción de urbanizaciones cerradas.

McKenzie (1994) analiza el poder creciente de las asociaciones de propietarios de comunidades cerradas, considerando este hecho como la expresión más clara del proceso de privatización del espacio público que caracteriza a las ciudades norteamericanas, representando un gran riesgo para la estabilidad de la comunidad ya que son estas asociaciones privadas quienes crean mayores controles y normas a los propios residentes de las urbanizaciones en cuestión.

b) En Latinoamérica, la expansión del urbanismo residencial cerrado es producida en la mayor parte de las grandes metrópolis, tales como Buenos Aires, Santiago, São Paulo y la Ciudad de México. Resulta interesante el estudio de Svampa (2001), quien plantea que Buenos Aires ha sido campo de un creciente proceso de segregación espacial expresado por el acelerado y cuantioso aumento de los barrios cerrados a partir de 1989, bajo un ambiente de incertidumbre social, violencia y criminalidad, a los que nombra "los espacios de los ganadores y los perdedores" (Svampa, 2001, p. 39). São Paulo es considerada por Caldeira (1998) como una de las urbes con mayor desigualdad en la distribución de la riqueza a nivel mundial. Menciona que el fenómeno de los enclaves fortificados (como le conocen en Brasil) ha tenido repercusiones en los últimos 15 años directamente en lo social-como consecuencia de la imposición de esta nueva forma de segregación espacial-, transformado la vida pública de la ciudad debido a la influencia material y simbólica que ejercen. Borsdorf (2003) realiza un interesante análisis y descubre que la tipología del modelo de urbanización cerrada tiene sus motivaciones en la etapa más reciente de la historia, aportando opiniones de gran valor al advertir la formación de un nuevo orden y sentido de concepción de la ciudad, centrando como factor causal la proliferación de FCR rodeados de vallas que expresan la inaccesibilidad urbana, la exaltación de la exclusividad, el prestigio social, la escasa o nula interacción entre los grupos sociales y el poco aprovechamiento de la infraestructura y del equipamiento urbano. En este grupo de investigadores se encuentran Rodríguez y Arriagada (2004), Roitman (2004), Prevot (2000) y Janoschka (2003), partidarios de considerar que los FCR son consecuencia y no causa de la fragmentación 
espacial, debido a la liberación del mercado del suelo, al proceso de globalización, a la desigualdad social y a la segregación con la que hoy se construyen las ciudades.

c) Los estudios en México están adquiriendo su propia identidad porque ya cuentan con marcos básicos de referencia (Enríquez, 2007), de allí la importancia de los estudios de Cabrales-Barajas y Canosa (2001) en Guadalajara; de Capron y Esquivel-Hernández (2016) en la Zona Metropolitana del Valle de México; García-Peralta (1986) en Querétaro, y finalmente los estudios de Méndez y Rodríguez (2005) y Mendoza Terrazas y Sánchez Flores (2009) en las ciudades de la frontera noreste de México, en donde la inserción de este fenómeno urbano y su comportamiento son particularmente distintos al tener a muy poca distancia el paisaje urbano de las ciudades fronterizas de Estados Unidos.

\section{Ubicación de la Zona Metropolitana del Sur de Tamaulipas. Área de estudio}

La Zona Metropolitana del Sur de Tamaulipas (ZMST) está integrada por las ciudades de Tampico, Madero y Altamira. Colinda al norte y noreste con los municipios de Aldama y González en el estado de Tamaulipas, al oriente con el Golfo de México, al sur con el estado de Veracruz y el río Pánuco, y al oeste con el estado de San Luis Potosí (véase la Figura 1). La superficie de estudio es de $1792 \mathrm{~km}^{2}$, distribuidos de acuerdo con el Cuadro 1.

Tampico y Madero son los municipios más pequeños del Estado de Tamaulipas, con $48.46 \mathrm{~km}^{2}$ y $114.52 \mathrm{~km}^{2}$ respectivamente; en cambio Altamira tiene mayor superficie territorial, con $3819 \mathrm{~km}^{2}$,y es el cuarto municipio más extenso del estado. Entre sus atributos geográficos se encuentran sistemas hídricos como: el río Pánuco y el Tamesí, numerosas lagunas urba-

\section{Cuadro 1}

Superficie y población de Tampico, Madero y Altamira, Tamaulipas

\begin{tabular}{llccc}
\hline Localidad & $\begin{array}{c}\text { Superficie } \\
\text { municipal }\end{array}$ & Porcentaje & $\begin{array}{c}\text { Núm. } \\
\text { de habs. }\end{array}$ & $\begin{array}{c}\text { Densidad } \\
\text { de habs. }\end{array}$ \\
\hline Altamira & $1661 \mathrm{~km}^{2}$ & 91.22 & 235066 & $141.52 \mathrm{habs} . / \mathrm{km}^{2}$ \\
Tampico & $62.86 \mathrm{~km}^{2}$ & 4.22 & 209175 & $3327 \mathrm{habs} . / \mathrm{km}^{2}$ \\
Madero & $68.10 \mathrm{~km}^{2}$ & 4.56 & 314418 & $4617 \mathrm{habs} . / \mathrm{km}^{2}$ \\
Total & $1792.70 \mathrm{~km}^{2}$ & 100.00 & 758659 & \\
\hline
\end{tabular}

Fuente: Elaboración propia con base en el Plan Municipal Desarrollo, 2013-2016. 


\section{Figura 1}

Ubicación de la Zona Metropolitana del Sur de Tamaulipas

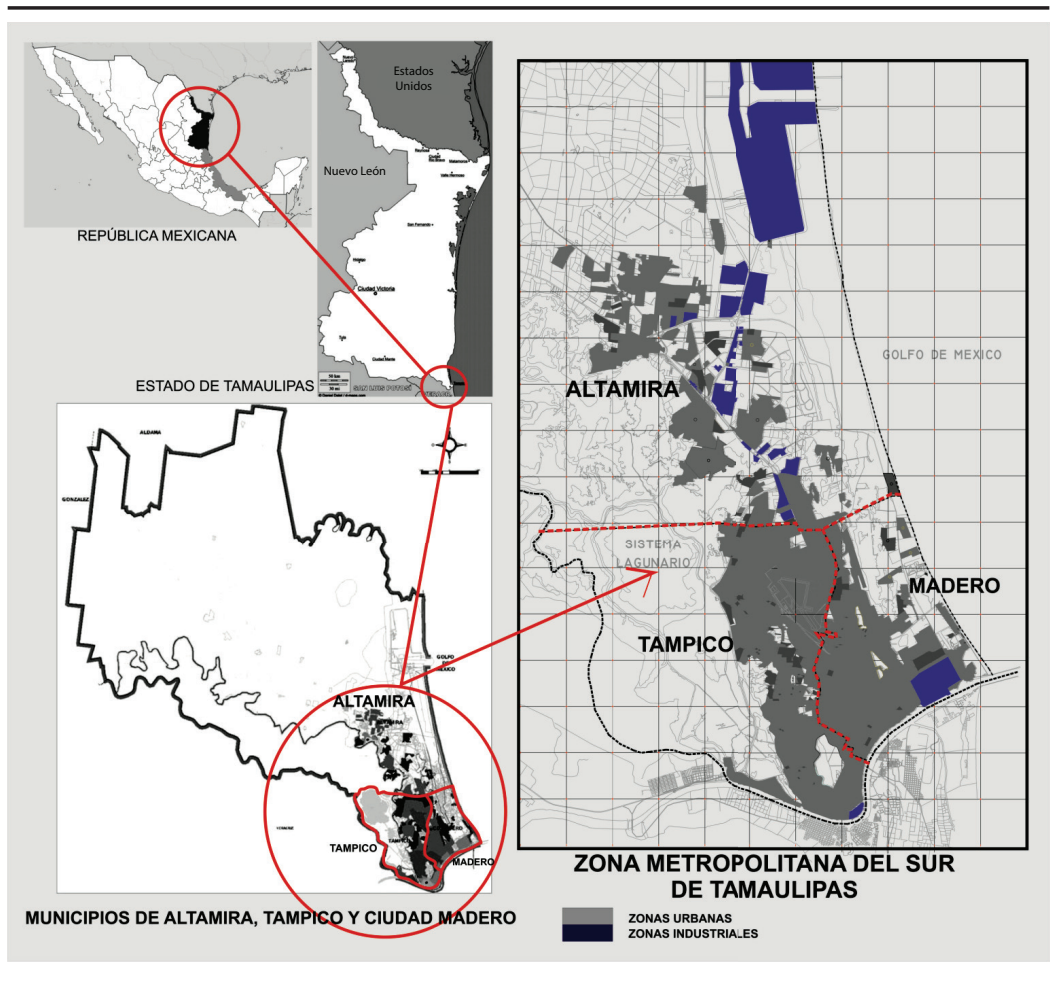

Fuente: Elaboración propia con base en el Programa Metropolitano de Ordenamiento Territorial de Altamira, Ciudad Madero y Tampico (2010).

nas, el gran humedal del río Tamesí y su sistema lagunario (Hurtado Baker, 2014), los cuales ejercen un importante impacto en las formas de crecimiento y expansión de la ciudad, así como en la vulnerabilidad de ciertas zonas hoy convertidas en emplazamientos urbanos en riesgo de inundación.

\section{Generación y reproducción del urbanismo cerrado en la ZMST}

La intromisión del urbanismo cerrado, de acuerdo con el concepto de exclusividad y acceso controlado, fue identificado a principios del siglo XX en el sur de Tamaulipas con la llegada de empresas petroleras extranjeras a Tam- 
pico, al fundarse en ese tiempo las colonias residenciales en donde sus ocupantes eran exclusivamente empleados de tales empresas, con cargos de medio y alto rango, lo que nos indica que dicha disposición de privacidad y exclusividad con sus respectivas limitaciones conceptuales no son del todo desconocidas para la región. Pocos son los vestigios que aún se conservan de este antiguo planteamiento urbano, entre ellos aún prevalecen: la colonia Águila, localizada en un predio distante $4 \mathrm{~km}$ del centro urbano de Tampico y a $11 \mathrm{~km}$ de la refinería (ubicada en Villa Cecilia, hoy Ciudad Madero). Las residencias fueron diseñadas según los estilos arquitectónicos ingleses, de buena calidad, buenos materiales y con una planeación previa.

En Ciudad Madero aún prevalece la colonia $1^{\circ}$ de Mayo, de acceso controlado, con la misma función de origen: dedicada a los técnicos y personal más solicitado para el manejo práctico de las refinerías.

Es a partir de 1990 que en la ZMST aparece por primera vez un FCR denominado Lagunas de Miralta (929 lotes), localizado en la periferia de Altamira, dirigido a la población de mayores ingresos; entre sus atractivos sobresalen la ubicación colindante con la laguna del Chairel, así como la magnitud de sus residencias (con una dimensión superior a los $300 \mathrm{~m}^{2} \mathrm{de}$ construcción), con buena calidad de materiales, diseño arquitectónico y lotificación promedio arriba de los $700 \mathrm{~m}^{2}$.

Lagunas de Miralta está provisto desde su origen con ciertos elementos representativos de exclusividad, tales como: caseta de control en el acceso principal, personal de vigilancia, segundo acceso restringido sólo a $500 \mathrm{~m}$ de distancia del primero, extensas áreas de esparcimiento, piscina, canchas deportivas y campo de golf. El proyecto urbanístico está conformado por tres zonas de distinto nivel habitacional, publicándose en la fase de preventa la construcción de torres departamentales de lujo con más de cuatro niveles de altura.

A partir de entonces y durante los siguientes 25 años fueron multiplicándose los FCR en la zona metropolitana; surgieron Las Villas (colindantes con Lomas de Rosales, zona urbana de alta plusvalía en Tampico), un conjunto residencial integrado por un sistema de nueve FCR, tres de ellos (Villa Encantada, Villa Dorada y Villa Vera) representan la mayor cantidad de predios (los de mayor tamaño), mientras el resto está formado por pequeñas agrupaciones de seis a ocho residencias agrupadas mediante barda perimetral y control de acceso.

Posteriormente siguieron Los Encinos en Altamira; Los Almendros, Jardines del Valle Club Residencial y Haciendas del Rull, en Tampico; finalmente, está el caso del Club Náutico en Altamira, constituido por cuatro diferentes FCR, cada uno con su propio sistema de control de acceso, colindantes unos con otros. 
Los desarrollos habitacionales de cualquier nivel que se construyen en la ZMST siguen en su mayoría las pautas del modelo de FCR, bajo el régimen de condominio. Actualmente y como una derivación del FCR, se produce el cierre de colonias, secciones de ellas y calles (anteriormente abiertas), emulando dicho concepto al limitar el libre tránsito por la ciudad.

Hacia finales de los noventa, la desregulación de la política en el sector habitacional en México se hizo más intensa, mostrando gran apertura a la presencia de promotores desarrolladores de vivienda en el mercado habitacional, cuya estrategia planteó que el papel del gobierno en el sector vivienda era desempeñar el papel de facilitador ${ }^{1}$ (Puebla Cadena, 2002) y no benefactor, como en épocas anteriores, que junto con la modificación del artículo 27 constitucional, favorecieron la expansión urbana al permitir la comercialización de tierras ejidales, liberando a las ciudades del cinturón urbano que las contenía. Es cuando llegan a Tampico grandes empresas del ámbito nacional e internacional con el objetivo de producir vivienda de manera masiva.

A finales de los noventa, la constructora Casas Geo adquiere terrenos cercanos a la laguna de El Champayán y produce uno de los FCR de vivienda de interés social más grandes de la zona, denominado Lagunas Florida I y II (5 650 viviendas) y dos fraccionamientos cerrados más: Villas de Altamira (700 viviendas) y Villa de las Flores (300 viviendas), todas bajo el concepto de fraccionamiento cerrado.

Posteriormente, en el año 2006, con una inversión de 60 millones de dólares, la misma empresa produce siete nuevos FCR de vivienda de interés social y de vivienda de nivel medio: el fraccionamiento Nuevo Campanario, en Altamira; Joyas de Miramápolis I y II, Joya Esmeralda y Joya Diamante Residencial, en Ciudad Madero; así como los fraccionamientos Bancario Residencial y Jardines del Valle Club Residencial, en Tampico. En el año 2008, Casas Geo inició los proyectos de los FCR del Náutico Residencial, Villas Náutico, Sotavento y Punta Laguna en la periferia de Altamira, al borde de la Laguna de Miralta, dirigidos a distintos niveles económicos (alto, medio y bajo).

Este modelo parte de una idea preconcebida desde el corazón mismo de la empresa. Carlos García Vélez y Cortázar, quien fuera vicepresidente de diseño de la Corporación Geo, S.A de C.V. en el año 2000, explica que este tipo de macro proyectos integrales tienen que ver con la escala, el equipa-

${ }^{1}$ Por facilitación se entiende "la creación de marcos legislativos, financieros, económicos e institucionales [...] [donde] los gobiernos tienen la responsabilidad de formular la política, realizar inversiones públicas y crear y proteger los derechos de la propiedad, es decir, facilitar el desarrollo del sector" de la vivienda (Puebla Cadena, 2002). 
miento, la infraestructura, la funcionalidad, el costo, la volumetría y la vivienda en particular; le denominan "La Morada", y se consideran distintas escalas con subsistemas interrelacionados que conforman un sistema integral, bajo la idea de que la volumetría se enriquece con la mezcla de diferentes prototipos de vivienda, pretendiendo integrar los distintos grupos sociales, como sucede en las ciudades.

Los FCR de tipo económico medio y medio bajo resultan ser los más emblemáticos. La condición de régimen de condominio les permite la acumulación de una gran cantidad de viviendas dispuestas en forma individual, en hilera o en módulos cuadrados, en cuyos centros se encuentra el equipamiento y los servicios, dejando margen para las áreas verdes.

Las viviendas se presentan en bloque, adosadas o individuales, de tipo económico, en formatos denominados dúplex, cuádruplex, séxtuples y óctuples, con pequeños departamentos de entre 40 y $54 \mathrm{~m}^{2}$, que repercuten en la muy ajustada espacialidad interna de las habitaciones, pero con las ventajas de poseer los servicios mínimos de infraestructura, participar de las áreas verdes y contar con la seguridad de la muralla. En esta categoría se mencionan: Los Mangos (desarrolladora Tercer Millenium), con capacidad de 2058 viviendas; Los Olivos (desarrolladora Aryve), con una capacidad de 4116 viviendas; el FCR Sotavento (Casas Geo), con capacidad de 1048 viviendas; y los Obeliscos (Casas Geo), con capacidad de 1004 viviendas, en Altamira.

\section{Metodología}

Para el análisis de las lógicas de inserción de los FCR en la ZMST, se desarrolla una investigación descriptiva.

La investigación corresponde al análisis espacial urbano que mediante indicadores cuantitativos y cualitativos pretende obtener el conocimiento de los elementos que identifican a las unidades de estudio y sus localizaciones de inserción. Se establecen en principio las características básicas de las unidades de estudio: los fragmentos cerrados residenciales (FCR), determinándose una selección no probabilística de muestreo discrecional, debido a la utilidad que le significa para la presente investigación una selección previa de unidades de estudio ajustadas a la definición que determina aspectos de forma, estructura, función, uso, dimensión y escala. Las unidades de estudio son los FCR insertados en la ZMST, emplazados en distinta proporción sobre las tres ciudades que integran la zona, sumando 55 FCR en Tampico, 19 en Altamira y 26 en Ciudad Madero. 
En primer término se ubicaron en el mapa de la ZMST las localizaciones de los FCR, posteriormente se calcularon las superficies de cada fragmento, realizándose en la cartografía la caracterización espacial de cada uno de ellos. Para la determinación de las lógicas de inserción se definieron cuatro tipos de inserción o emplazamientos diferenciados: 1) dentro de las tramas de la ciudad, 2) en los lugares del borde urbano, 3) en los sitios intersticiales, y finalmente, 4) los insertados sobre la periferia tomando en cuenta las variables de análisis seleccionadas, tales como: la forma del perímetro, la superficie, la dimensión del perímetro, el uso urbano del fragmento, la densidad residencial, la tipología de colindancia, el número de viviendas, su posición respecto a los centros urbanos más próximos, las localizaciones de riesgo y los tipos de colindancias (véase la Figura 2).

En la Figura 2 de la ZMST se localiza la posición de emplazamiento de los FCR, señalados con puntos negros contenidos dentro de las figuras de cuadro, círculo y triángulo; del lado derecho del mapa destacan los kilómetros de distancia y con franjas obscuras se definen intervalos a cada $5 \mathrm{~km}$ de separación. Se distinguen dentro de la figura triangular los FCR en un entorno de contraste, ya que la generalidad del nivel de vivienda en esa zona es del tipo económico y de interés social, en contraste con FCR de nivel económico muy alto. Dentro de la figura cuadrada se encuentran los FCR en la periferia de Altamira (zona de expansión urbana); ésta es la zona que mantiene la mayor diversidad y contraste de FCR, encontrándose tanto las de mayor superficie con vivienda social, como las de vivienda tipo medio, residencial y campestre. Finalmente, dentro de la figura del círculo se concentra una considerable cantidad de FCR, la mayoría localizados en una de las zonas de mayor plusvalía en Tampico.

\section{Análisis de la lógica de inserción de los FCR en la ZMST}

Los FCR son un fenómeno urbano claramente visible que se concentra en distinta proporción entre Tampico, Madero, Altamira y su periferia de la ZMST. En Tampico se caracterizan por su presencia dentro de la trama urbana de la ciudad, en donde poco a poco se han subdividido las manzanas de la retícula preexistente y reutilizado lotes vacantes para dar cabida a FCR en su mayoría menores a una hectárea. En otros casos, se han ocupado los terrenos intersticiales para urbanizaciones más grandes; estos últimos se han emplazado de forma extendida y caprichosa sin tener que ordenarse bajo las alineaciones de calles o de lotificaciones, provocando cortes permanentes en la continuación de la trama urbana o en la comunicación intermetropolitana. 


\section{Figura 2}

Emplazamiento de los FCR en la ZMST

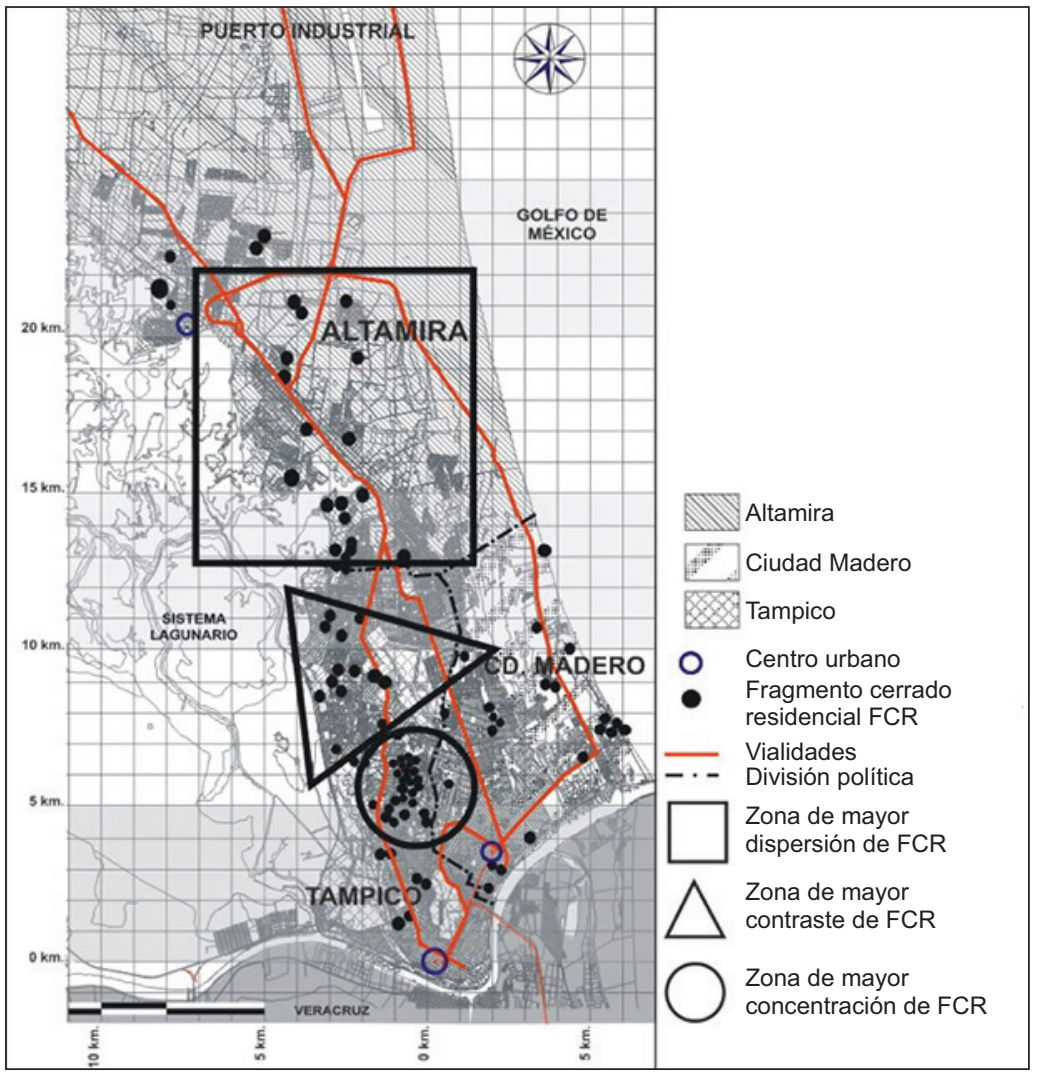

Fuente: Elaboración propia.

En Ciudad Madero la mayor parte de los FCR se encuentran insertados en la trama urbana; la reutilización de lotes, con construcciones abandonadas en su mayoría, ha servido como espacio para la construcción de estos nuevos productos urbanos. Llama la atención el carácter aún habitacional de su centro urbano y la tendencia a la gentrificación, que moderadamente se ha emprendido con la inserción de FCR localizados en los primeros cuadros de la ciudad, desplazando el caserío de madera de principios de siglo XX por urbanizaciones cerradas tipo nivel medio, brindándole un aspecto más renovado a la ciudad. 
En Altamira resulta preocupante el emplazamiento de los FCR en la periferia, con riesgos de inundación y esparcidos sobre un territorio muy distante de la ciudad.

Existen en la zona de estudio fragmentos urbanos residenciales que pueden considerarse cerrados debido a su configuración sociourbana. Esto se explica porque son exclusivamente para determinados grupos sociales o familiares, lo que significa que sólo miembros pertenecientes a una misma asociación -ya sea de trabajo, de sindicato o línea familiar- pueden vivir dentro del recinto; formalmente se encuentran amurallados y controlados en su acceso.

La forma de los FCR puede variar y su tamaño también, dependiendo de lo extensivo de la propiedad; de igual manera, la trama vial varía partiendo desde un acceso sin retorno o cul de sac en donde las propiedades se alinean a la calle sin mayores complicaciones, hasta complejas propuestas viales. Otros FCR se caracterizan por estar insertos en las manzanas que forman la cuadrícula de la ciudad; en este caso, la posibilidad de crear un conjunto de esta naturaleza se debe a la gestión inicial de la subdivisión de lotes. Finalmente, se han identificado colonias que originalmente fueron abiertas, pero en la actualidad han sido cerradas, se han instalado casetas de vigilancia privada y se clausuró el resto de los accesos.

\section{Construcción de una tipología de FCR partiendo de una lógica de inserción urbana}

Para la construcción de una tipología a partir de una lógica de inserción centro-periferia es necesaria la localización de los FCR dentro de un marco en el que se definen las particularidades de cada emplazamiento. Para esto se determinaron cuatro variables de posición de inserción: insertos en la trama urbana, sobre territorio de intersticio, emplazados en los bordes de la ciudad (línea perimetral que define el territorio urbano compacto del territorio en expansión) y los emplazados de manera dispersa en la periferia. Los tipos de emplazamiento se exponen en las siguientes formas:

FCR insertados en la trama urbana (T-UR). Estos fragmentos se insertan dentro de las manzanas preexistentes de la ciudad. La trama urbana se forma mediante la disposición de los edificios con respecto a las calles; puede presentarse de dos maneras: como una trama compacta o cerrada cuando los edificios se disponen unos junto a otros a lo largo de grandes extensiones, o bien, abierta cuando los edificios dejan amplios espacios libres entre ellos (Carrasco Aquino, 2000). Una trama urbana existe cuando hay vialidades que se entrecruzan entre ellas, formando fragmentos de espacios 
interiores denominados manzanas, de formas y tamaños adecuados para ser subdivididas en lotes propios de usos y tipologías urbanas; sin embargo, debido a la inserción de los FCR, se pone en riesgo el funcionamiento y viabilidad del sistema urbano de la trama.

FCR insertados en el espacio intersticial (IN). El concepto de intersticio tomado como una dimensión de análisis del territorio aparece como algo confuso y guarda múltiples significados en el estudio de las espacialidades urbanas contemporáneas; sin embargo, en este caso, intersticio se refiere a la situación espacial particular de los espacios vacantes emergentes dejados como remanentes por la superposición de nuevos ordenamientos urbanos que han surgido en un mismo sitio (Fariña, 2000).

FCR insertados sobre el borde (BO). Se le llama también perímetro o contorno y es interpretado como los límites definidos entre el campo y la ciudad. Se refiere a una situación intermedia entre dos tipos geográficos aparentemente bien diferenciados. Si bien es cierta la existencia de distintas disertaciones respecto al significado y los alcances atribuidos a este concepto, en el caso que nos ocupa el borde o perímetro se reconoce, según Pulido (2014, p. 20), como "la orilla que circunda la mancha urbana", ya que circunscribe o delimita lo urbano en la ciudad compacta del territorio extendido y fragmentado de la periferia. Desde el ámbito de la disciplina del urbanismo, la definición de borde dada por Lynch (1960, p. 62) considera que:

Es el límite entre dos fases, rupturas lineales de la continuidad, como vías del ferrocarril, bordes de desarrollo, playas, o muros [...] En dicha definición se representa al borde como una línea que separa dos espacios social y físicamente diferenciados y constituyen, bien sea una ruptura o una sutura de la continuidad urbana.

La situación espacial y urbana del borde o del perímetro de una ciudad generalmente es transitoria; esto se debe a que el borde urbano se encuentra en una permanente transformación con expectativas de cambio y es susceptible de nuevas intervenciones; lo mismo sucede con el concepto de periferia, cuya dinámica de evolución se define más plenamente con el tiempo.

FCR insertados en la periferia (PE). Para el presente análisis, la periferia es considerada como el ámbito en el cual se verifica la expansión desordenada de la ciudad:

[...] la periferia nace y se establece como fenómeno típico de la ciudad contemporánea, cuando las ciudades comienzan a expandirse más allá del perímetro [...] y el territorio se empieza a urbanizar por partes, alrededor de la ciudad consolidada [Arteaga-Arredondo, 2005, p. 99]. 
Es el territorio en el que se manifiesta con mayor evidencia la extensión residencial sobre el suelo a menor costo; es el lugar de la industria, el trabajo de masas, la planeación de nuevas vías de tránsito carretero, lugar de grandes centros comerciales, universidades y colegios privados.

Como se aprecia en la Gráfica 1, la mayoría del total de FCR en la ZMST (63\%) se sitúa dentro de la trama urbana; se caracterizan por su reducido tamaño (hasta 5 ha, según los parámetros de la clasificación de nuestro estudio), y suman aproximadamente 1852 viviendas. Los FCR de posición intersticial representan sólo $13 \%$, los de borde $14 \%$ y los de periferia $12 \%$; estos últimos son fragmentos de grandes dimensiones con vivienda social. Se observa también que en Tampico la mayor parte de las ubicaciones de los FCR se dan dentro de la trama urbana con 36\%; en Ciudad Madero, con 21\%; en Altamira sólo 12\% de los FCR se insertan en la periferia, con 11739 viviendas. Más de 26035 viviendas coexisten bajo las normas del urbanismo cerrado en la ZMST.

El riesgo de inundaciones en la ZMST afecta a un área de $28.67 \mathrm{~km}^{2}$ dentro de la cual se encuentran 93 colonias con aproximadamente 154450 habitantes (consúltese el Atlas de riesgos de Tampico, Madero y Altamira,

\section{Gráfica 1}

Lógica de inserción de FCR en la ZMST

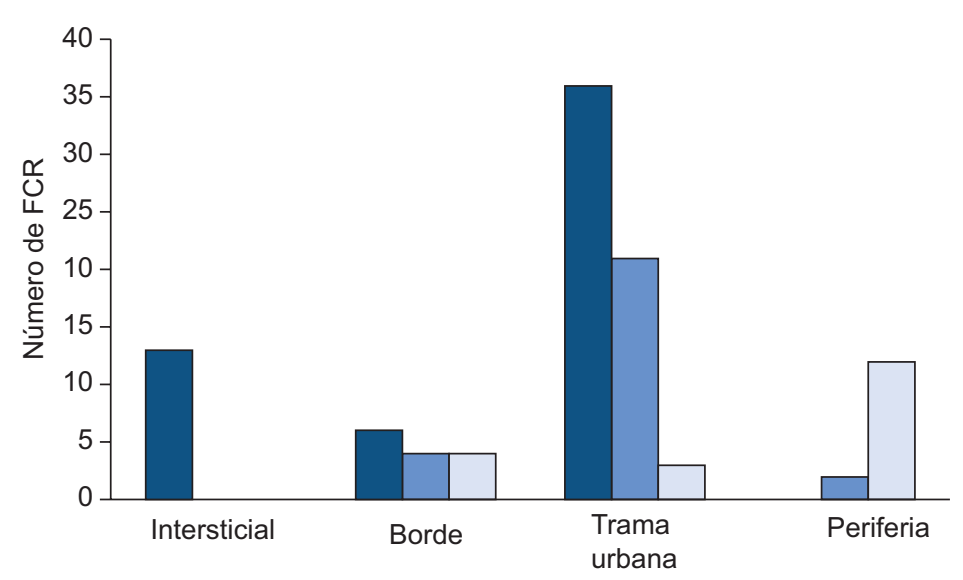

Tipología de lógica de inserción

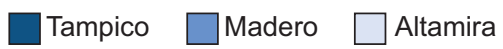


en Gobierno del Estado de Tamaulipas, 2009, pp. 100-112); del conjunto total de FCR, el 37\% (14 627 viviendas) está en riesgo de inundación (véase el Cuadro 2).

Lo anterior se debe a la incidencia de localización con mayor frecuencia de FCR en colindancia con cuerpos de agua como lagunas, ríos o cuencas y subcuencas hidrológicas de escurrimiento de gran volumen en Altamira y en Madero (véase el Mapa de Subcuencas Zona Metropolitana, plano clave ME-6, en Programa de Ordenamiento Territorial de Altamira, Ciudad Madero y Tampico, 2010a). En la Gráfica 2 se observa que en Altamira y Madero la mayoría de las colindancias de los FCR se relacionan con cuerpos de agua. Sin embargo, en Tampico la mayor incidencia de localización de los FCR sucede en colindancia con vías suburbanas, almacenes de comercio y edificaciones militares, debido esto último a la proximidad de una superficie de 48 ha destinada para campo militar.

\section{Forma del contorno perimetral, dimensión o tamaño y colindancias de los FCR}

La importancia del conocimiento de la forma de los FCR está directamente relacionada con la estructura del uso del suelo. La forma tiene un significado relevante debido a que entre más alargada sea la forma perimetral de los FCR, dará como resultado una menor compacidad y una mayor fragmentación; en el sentido contrario, cuanto más cercana es la forma a una figura circular, mayor será la condición de compacidad y menor la tendencia hacia la fragmentación (Aguilera-Benavente, 2010, p. 19). El cambio en la forma de los fragmentos a través del tiempo y de su crecimiento puede representar una mayor dispersión en la ocupación del suelo. Éstos son valores fundamentales en el análisis de la estructura del suelo o del paisaje urbano sostenido por las métricas básicas de la ecología del paisaje (McGarigal, Tagil y Cushman, 2009). De acuerdo con esto, como inicio se identifican las formas de los FCR mediante su geometría perimetral sujeta a distintas condiciones de orden natural como la propia topografía del suelo, las delimitaciones de los cuerpos de agua y de los elementos antrópicos, tales como la retícula urbana o los espacios intersticiales que aún permanecen en la ciudad.

Las formas perimetrales de los FCR de grandes dimensiones se encuentran ubicadas generalmente en la periferia; por el contrario, las pequeñas se insertan en la trama de la ciudad o en espacios intersticiales. Los FCR, desde los grandes hasta los pequeños, funcionan como entidades independientes debido a su condición amurallada y controlada, así como por otros 


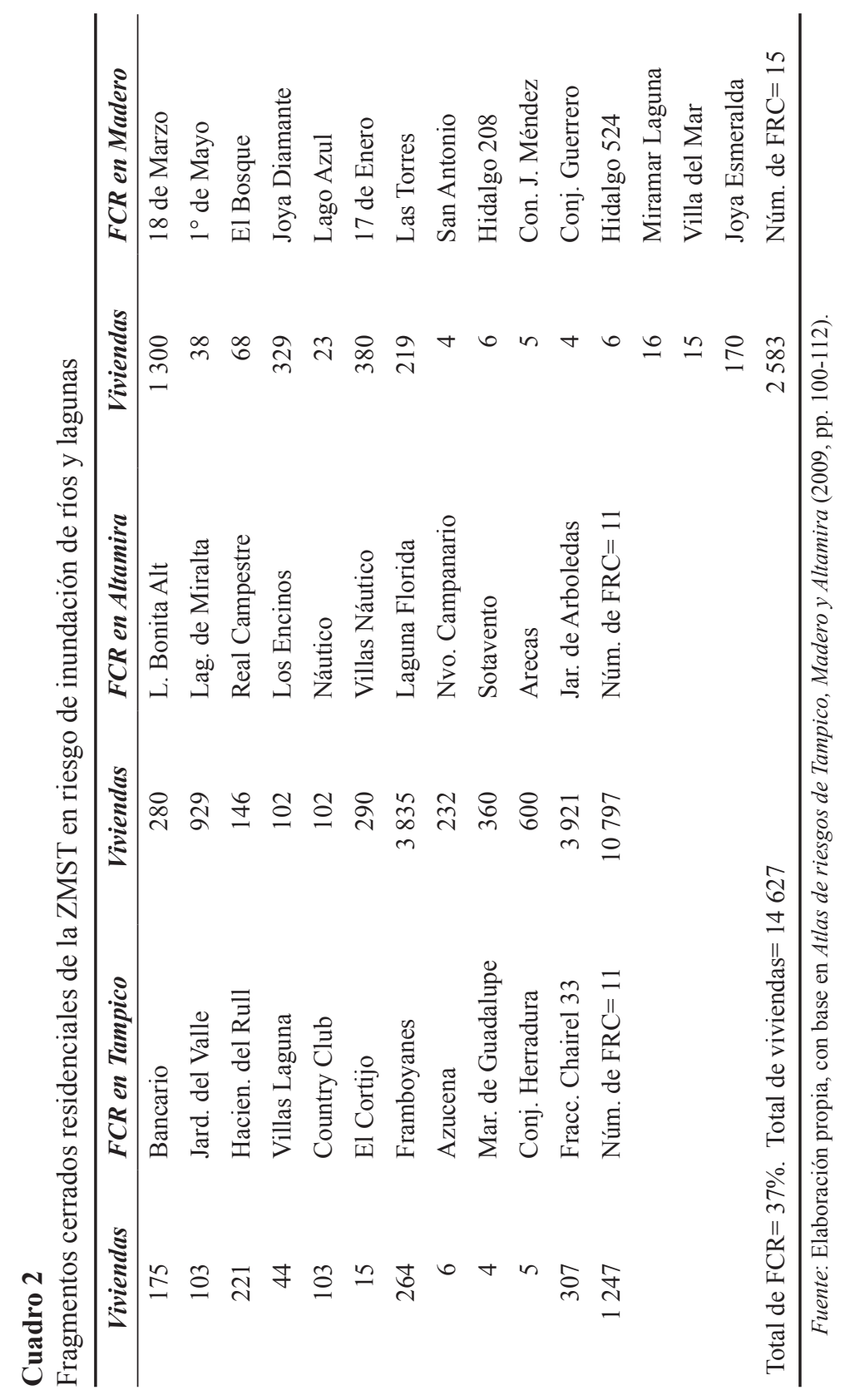




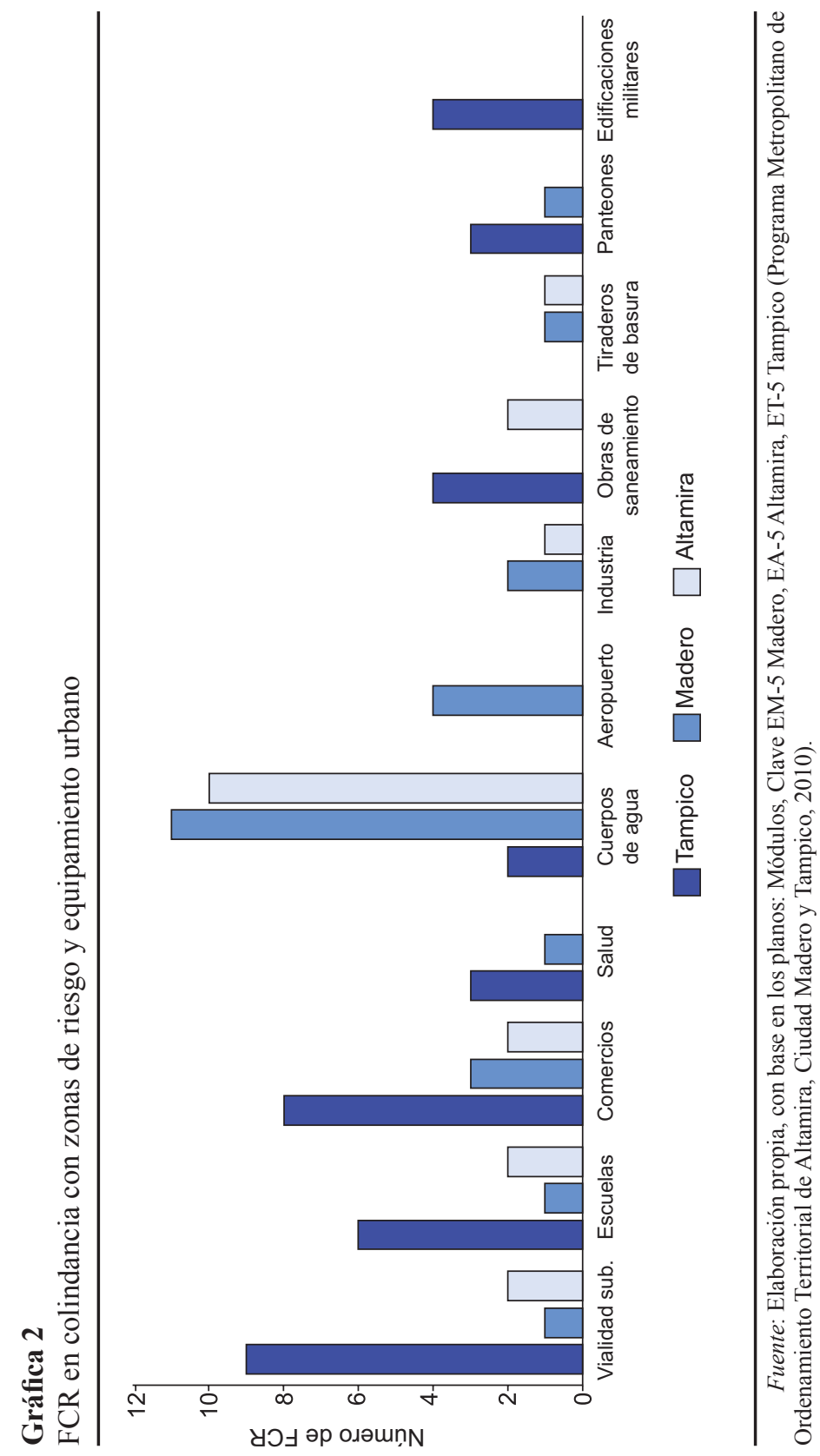


factores subjetivos que manifiestan sin palabras la prohibición de acceso al lugar. Se distinguen las siguientes formas de acuerdo con la clasificación de la geometría básica de los polígonos: polígonos regulares (lados y ángulos iguales) y polígonos irregulares (lados y ángulos desiguales) dentro de las formas geométricas artificiales; y finalmente las formas orgánicas (de la naturaleza), tomando como referencia las formas básicas del trazado urbano (Ducci, 1989, p. 57), excepto la radio-concéntrica por su ausencia en la zona de estudio.

En el Cuadro 3 los FCR de geometría regular son los de mayor presencia, con una ocupación de superficie de $48.10 \%$, la mayoría en la traza urbana. Los FCR de geometría irregular, aunque son más numerosos que los orgánicos, registran una superficie menor debido a que éstos también se encuentran en su mayoría dentro de la traza urbana y el valor del suelo es más caro que en la periferia. Los de forma orgánica poseen una superficie mayor, aunque son menos (42.68\%), ya que se trata de grandes FCR de vivienda social.

El análisis de la dimensión de la superficie de cada FCR es importante ya que está directamente relacionado con sus posibilidades de localización e incidencia en el entorno urbano. Este dato está relacionado con los fenómenos de fragmentación y de agregación urbana debido a que el tamaño medio del total de conjunto de FCR, junto con el número de ellos, aporta un dato relevante sobre los niveles de fragmentación del mismo uso residencial, por lo que el incremento en el número de fragmentos, junto con una disminución del tamaño medio de éstos, indica un incremento de la fragmentación; por el contrario, una disminución del número de fragmentos con un aumento del tamaño medio de los FCR indica una tendencia hacia la agregación urbana (Alberti y Marzluff, 2004).

Se observa en la Gráfica 3 una mayoría de replicación de FCR con superficies hasta 5 ha en $68 \%$ con geometría regular (más próximo a una circunferencia); generalmente este tipo de FCR se encuentran dentro de la trama urbana de Tampico y Madero con 36 y $21 \%$, respectivamente. En la Figura 3 se aprecian algunos FCR insertos en la ZMST, con datos de superficies, forma, perímetro, tipología de vivienda, municipio, tipo de localización, cantidad de vivienda, tipología de densidad urbana y tipo de colindancias.

En el análisis del entorno, los factores de vecindad en colindancia con los FCR son elementos determinantes de valorización, ya que son considerados como uno de los elementos más emblemáticos para definir las lógicas de inserción del nuevo producto urbano, así como también a la hora de elegir el tipo de vecindario con el que se prefiere convivir. De acuerdo con 


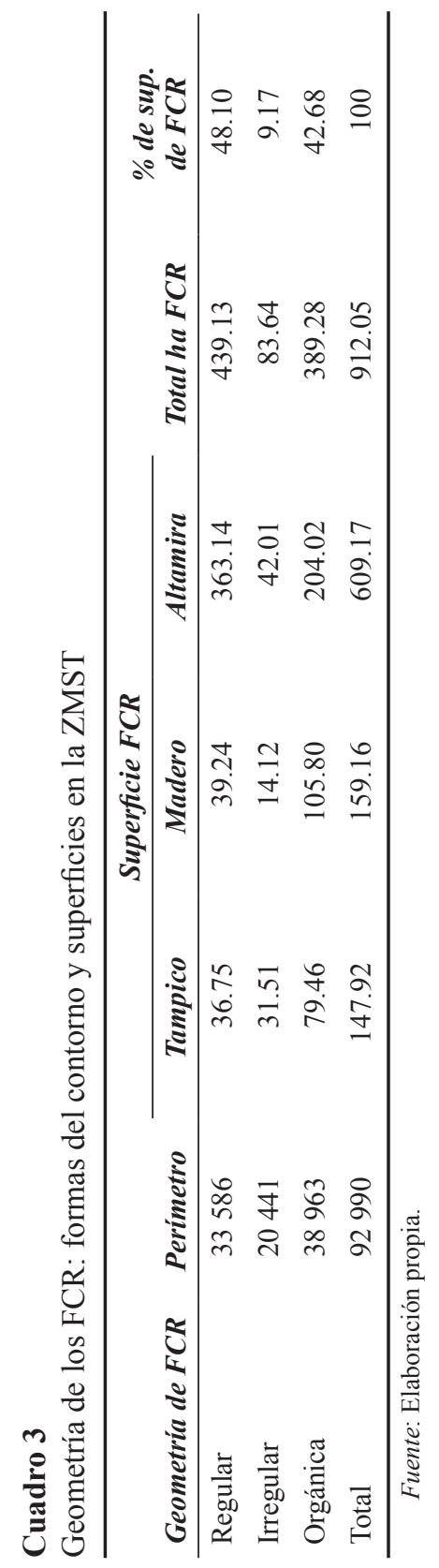




\section{Gráfica 3}

Superficies de ocupación según tamaño de los FCR en la ZMST

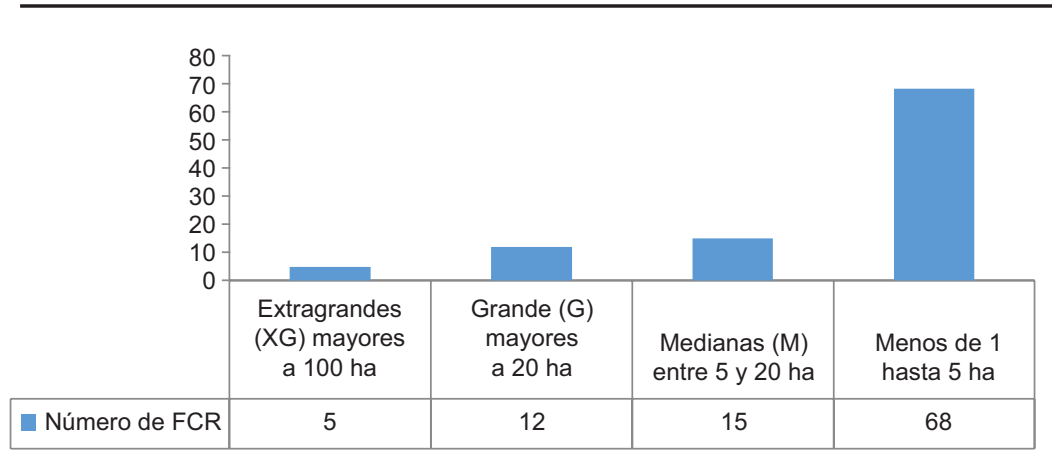

Fuente: Elaboración propia.

el análisis, es posible concluir las situaciones de contraste entre fragmentos urbanos y las situaciones de riesgo en que se posicionan sobre el territorio.

En la Gráfica 4 se puede observar que la lógica de inserción de FCR en Tampico tiene mayoría en zonas de densidad baja y de densidad residencial (Programa Metropolitano de Ordenamiento Territorial de Altamira, Ciudad Madero y Tampico 2007-2012, p. 59), así como también en las zonas intersticiales. En Altamira las inserciones de FCR, en su mayoría de vivienda social, están en suelo vacante de la periferia.

\section{Resultados de análisis de la lógica de inserción de los FCR en la ZMST}

En Altamira se manifiesta la tendencia a elegir lugares de inserción de acuerdo con las zonas menos valorizadas de la región debido a su riesgo de inundación o suelo barato de antiguos ejidos, ${ }^{2}$ las zonas más alejadas en la periferia, y las zonas con mayor contraste entre el nuevo producto residencial y su entorno, produciéndose una particular fragmentación del espacio urbano, en donde a pesar de que los grupos socioeconómicos se encuentran más cercanos unos de otros, en realidad están "separados por muros y tecnologías

2 Se autoriza la venta de tierras ejidales a partir de la modificación del artículo 27 de la Constitución Federal y de la reforma a la Ley Agraria en 1992 en México, y se empiezan a comercializar vastas extensiones de tierras, dando pie, entre otros factores, al surgimiento de los conjuntos urbanos de vivienda de interés social. 


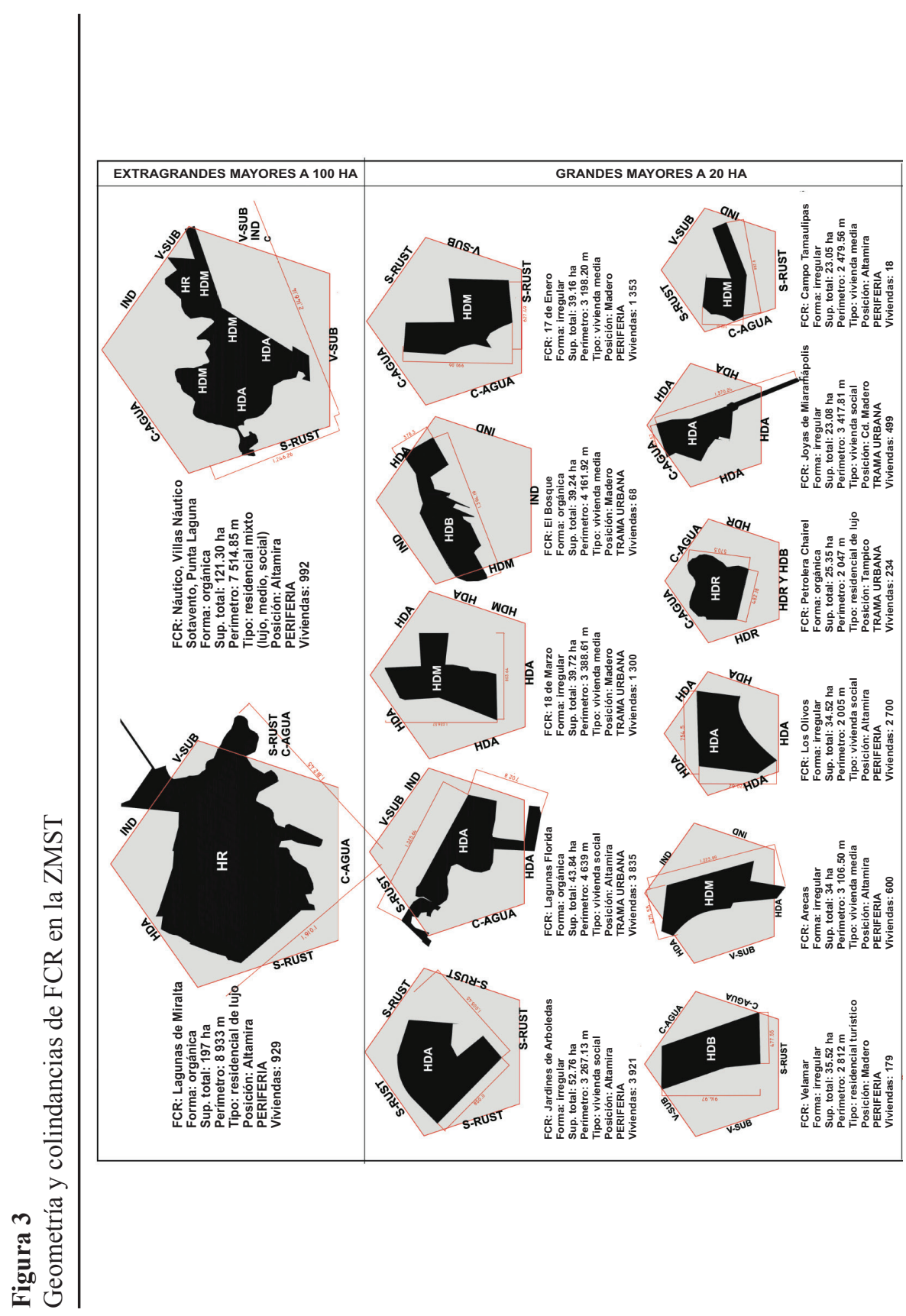



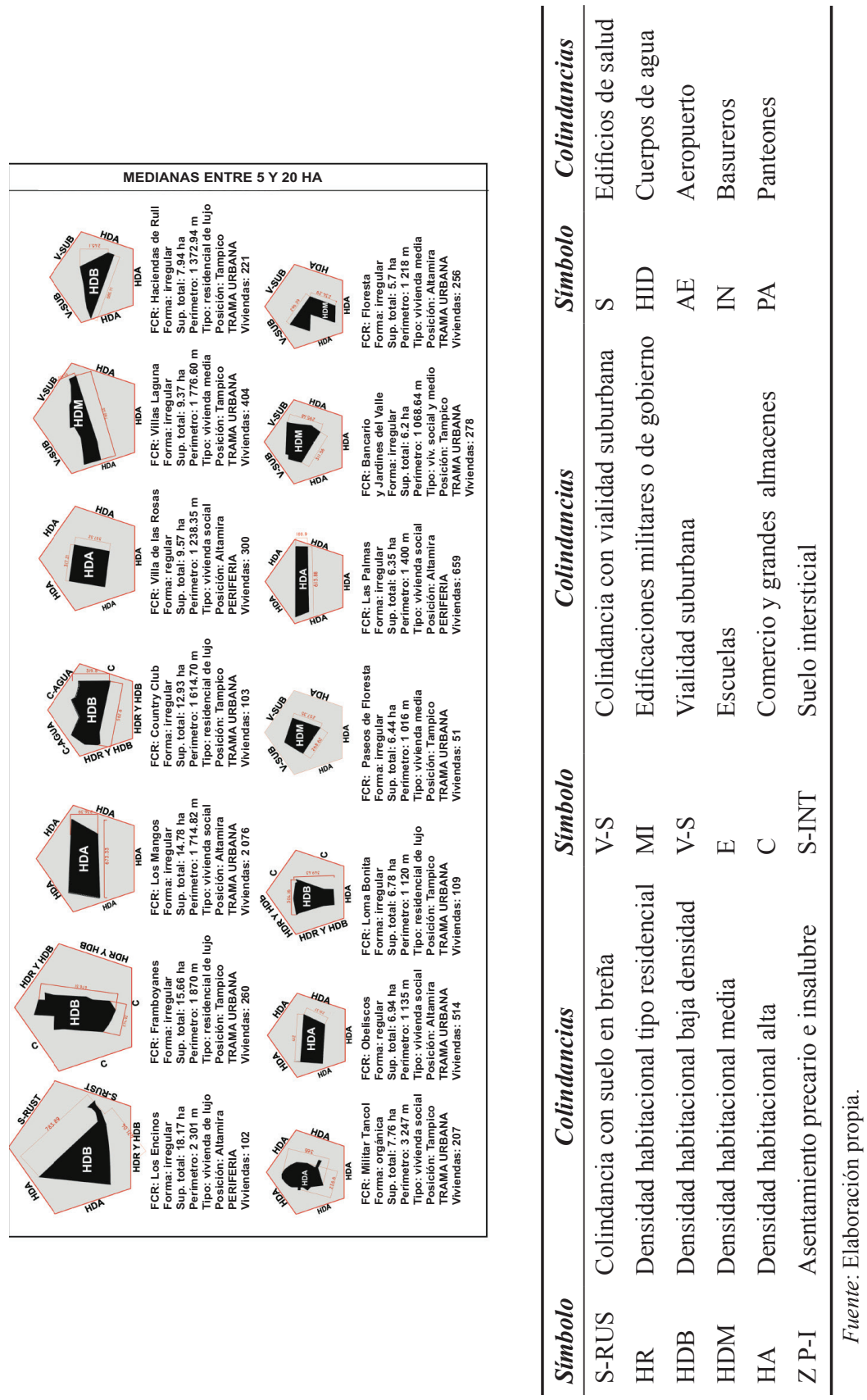


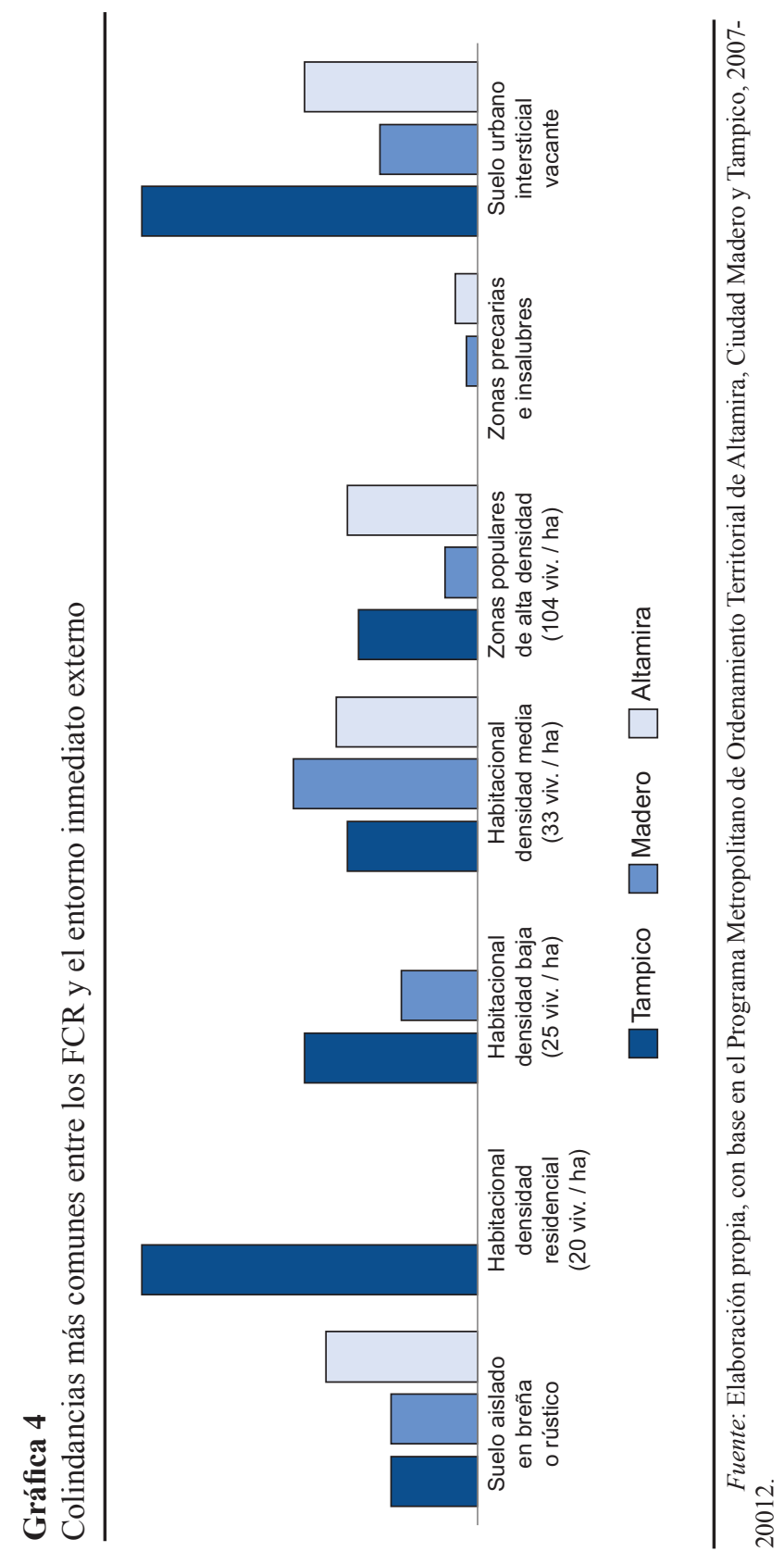


de seguridad", tal y como lo explica Hidalgo (2004, p. 31). Esto significa que, debido a una lógica de inserción emplazada sobre la periferia, encierra distintas características que la convierten en un territorio de suelo disponible, barato, con espacio extenso y con las facilidades para un mercado exitoso preferentemente para las inmobiliarias como Casas Geo (principal constructora de vivienda en FCR en la periferia de la ZMST), que cuentan con las nuevas políticas de vivienda y financiamiento de interés social para la adquisición de dicho patrimonio, en donde "las empresas privadas se encargan de la producción de viviendas y los organismos públicos se encargan de crear la demanda [solvente]", según palabras de Capron, y Esquivel-Hernández (2016, p. 133). La lógica de inserción de los FCR en la periferia con respecto al distanciamiento de la ciudad plantea que mientras para ciertos grupos representa una ventaja o un privilegio, para el resto de los habitantes tiene implicaciones relacionadas con el transporte y el equipamiento insuficiente, dando motivo para iniciar el regreso a la ciudad.

En Tampico llama la atención el impacto de una mayor fragmentación urbana producida por efecto de la inserción de la mayoría de FCR dentro de la trama urbana en un área de alto nivel socioeconómico denominada Zona Dorada, cuyas características más sobresalientes son su posicionamiento en el mapa y la calidad de sus viviendas (sin equipamiento, sin zonas verdes, piscina o cualquier otro equipamiento como atractivo). Bajo esta condición, más del $80 \%$ de los FCR de Tampico se conjugan en una especie de conflagración y estado de alerta, en donde no se manifiesta el contraste socioeconómico porque en general son de la misma tipología residencial, pero sí ejercen un aumento en la "insularización" (Capron y Esquivel-Hernández, 2016) o fragmentación de dicha zona.

En Ciudad Madero es notable la iniciativa de una reconversión urbana, cambiando el parque habitacional obsoleto por una gentrificación moderada al insertar en su centro urbano FCR, los que han mejorado la imagen de la ciudad respetando el perímetro circundante según la Ley de Desarrollo Urbano y eliminando la muralla perimetral por la alineación de residencias. Finalmente, se mantiene viva en Ciudad Madero la prevalencia de criterios de inserción de FCR en zonas bajas, inundables y alejadas de la ciudad (hacia la parte oeste, sobre lagunas urbanas) promoviendo la expansión y la fragmentación urbana con la incidencia de FCR de vivienda social en la periferia, situación que cíclicamente expone la mala planeación de la ciudad. 


\section{Conclusión}

Los FCR son un fenómeno con fundamentos y motivaciones diversas y particulares que difícilmente desaparecerán del escenario urbano en el futuro; su presencia se debe a un cúmulo de factores que se conjugan en numerosas ciudades que padecen en general condiciones similares de la nueva realidad global. La lógica inicial de los FCR enfocada sólo a los más privilegiados, a los nuevos habitantes de la periferia convencidos de un nuevo modelo de vida centrado en la exclusividad y en medio de la naturaleza, siguiendo patrones de autosegregación y otras ventajas, hoy colindan con FC de vivienda de interés social de gran tamaño u otras comunidades de contraste, prevaleciendo una evidente fragmentación urbana en la periferia, profundizando de este modo el aislamiento y la distancia social entre ellos mismos y la ciudad central. Sin embargo, la desventaja de compartir una misma lógica de inserción de ambos emplazamientos urbanos en la periferia radica no sólo en lo anterior, sino que mientras los ricos gozan de todo tipo de privilegios y potencialidades, para el resto de los habitantes el costo del aislamiento es muy alto, debido a las enormes distancias entre ellos y la ciudad, los riesgos de inundación, los insuficientes servicios básicos, la falta de seguridad y la aparición de la nueva violencia urbana. Todo lo anterior presenta una dicotomía: por una parte, para ciertos grupos sociales dicha lógica de inserción de FCR representa una ventaja, casi una oportunidad para el lucimiento del automóvil propio; pero para el resto de los habitantes en esa misma situación tiene implicaciones que relacionan el salario con los altos costos del transporte y el gasto del tiempo en traslados, dando pie finalmente al abandono de sus viviendas y a la pérdida de su patrimonio.

Existen diferencias sustanciales acerca de la aplicación y funcionalidad del concepto de condominio y las normas internas. Por una parte, los FCR de los más privilegiados se ajustan a la estructura y función acordada de conjunto, con el respaldo de una economía suficiente para el mantenimiento y los servicios; pero por el contrario, a los habitantes de los FCR de vivienda social les resulta complicado el no contar ni con los recursos ni con la preparación para organizarse, generándose diferencias y desacuerdos entre ellos.

Ciertamente, la ZMST aún se encuentra en ese estado de transición provocado por las transformaciones de la estructura urbana de la ciudad interna y con mayor fuerza por la expansión residencial hacia la periferia. Diariamente se transforman y se replantean subdivisiones de las antiguas manzanas de la ciudad, con el propósito de insertar algún FCR en lo ya lotificado, o emplazar en la periferia nuevos proyectos de FCR dependientes 
del automóvil privado o del transporte público que complican la situación urbana desde el centro hasta la periferia.

La tendencia de la construcción y la organización de la ciudad hoy en día mira hacia una dirección en donde el tema de la vivienda, la lógica de inserción y sus condiciones de funcionalidad responden sólo al interés del empresario y constructor de la ciudad privada: una ciudad compuesta de células aisladas, imponiendo un criterio propio para lograr un mejor negocio y mayores ganancias, por encima del interés comunitario de la ciudad y de sus habitantes en general.

\section{Bibliografía}

Aguilera Benavente, F. (2010). Aplicación de métricas de ecología del paisaje para el análisis de patrones de ocupación urbana en el Área Metropolitana de Granada. Anales de Geografia, 30(2), 9-29. Recuperado de http://revistas.ucm.es/ index.php/AGUC/article/view/31845

Alberti, M. y Marzluff, J. M. (2004). Ecological resilience in urban ecosystems: Linking urban patterns to human and ecological functions. Urban Ecosystems, 7(3), 241-265. Recuperado de https://pdfs.semanticscholar.org/b0df/fa3a 485c17f248f9fd074c3f7f5a0d0e739a.pdf

Arteaga Arredondo, I. (2005). De periferia a ciudad consolidada. Estrategias para la transformación de zonas urbanas marginales. Revista Bitácora Urbano Territorial, 9(1), 98-111. Recuperado de http://www.redalyc.org/pdf/748/74800909.pdf

Blakely, E. J. y Snyder, M. G. (1997). Fortress America: Gated communities in the United States. Washington D.C: Brookings Institution Press /Lincoln Institute of Land Policy / Atkinson y Blandy.

Borsdorf, A. (2003). Cómo modelar el desarrollo y la dinámica de la ciudad latinoamericana. Eure, 29(86), 37-49. Recuperado de http://www.scielo.cl/scielo. php?script $=$ sci_arttext\&pid=S0250-71612003008600002

Briceño Lara, R. (2016). Colección fotográfica de Tampico Antiguo. Recuperado de http://www.20minutos.es/museo-virtual/donantes/2790-rafael-briceno-lara/ (consulta: 9 de agosto de 2017).

Cabrales Barajas, L. F. (2002). Ciudades cerradas, mentes abiertas. En L. F. Cabrales Barajas (comp.), Latinoamérica: países abiertos, ciudades cerradas (pp. 11-16). México: Universidad de Guadalajara / UNESCO.

Cabrales Barajas, L. F. y Canosa Zamora, E. (2001). Segregación residencial y fragmentación urbana: los fraccionamientos cerrados en Guadalajara. Espiral, 7(20), 223-253. Recuperado de http://www.redalyc.org/articulo.oa?id=13802008

Cáceres, G. y Sabatini, F. (2004). Barrios cerrados en Santiago de Chile: entre la exclusión y la integración residencial. Santiago, Chile: Pontificia Universidad Católica de Chile. 
Caldeira. T. P. R. (1998). Fortified enclaves: The new urban segregation. En J. Holston (ed.), Cities and citizenship. Durham, NC: Duke University Press.

Capron, G. y Esquivel Hernández, M. T. (2016). El enclave urbano, lógica socioespacial de la periferia urbanizada y sus efectos sobre la segregación residencial y la fragmentación urbana. Cuadernos de Geografía. Revista Colombiana de Geografia, 25(2), 127-150. Recuperado de http://www.redalyc.org/articulo. oa? id=281846286007

Carrasco Aquino, R. J. (2000). Ciudad periferia urbana y capital. Ambiente Ecológico, 71. Recuperado de http://www.ambiente-ecologico.com/ediciones/07106-2000/071-roquecarrascoaquino.html

Castells, M. (1999). La era de la información. Vol. I. Economía, sociedad y cultura. México: Siglo XXI. Recuperado de http://www.felsemiotica.org/site/wp-content/ uploads/2014/10/LA_SOCIEDAD_RED-Castells-copia.pdf

Davis, M. (1999). Urbanismo mágico: los latinos reinventan la gran ciudad estadounidense. New Left Review, 3, 19-64. Recuperado de https://newleftreview.org/ article/download_pdf?id=1983 ylanguage=es

Ducci, M. E. (1989). Introducción al urbanismo. Conceptos básicos. México: Trillas. Enríquez Acosta, J. A. (2007). Ciudades de muros. Los fraccionamientos cerrados en la frontera noroeste de México. Revista Electrónica de Geografía y Ciencias Sociales, 11(230). Recuperado de http:/www.ub.edu/geocrit/sn/sn-230.htm

Fariña, F. S. (2000). Predios Urbanos Intersticiales (PUInt). Validación de herramienta de análisis-diagnóstico. Antecedente y generación de hipótesis teóricas fundantes de procesos proyectuales alternativos. La Plata, Argentina: Universidad Nacional de La Plata.

Flusty, S. (1994). Building paranoia: The proliferation of interdictory space and the erosion of spatial justice. West Hollywood, CA: Los Angeles Forum for Architecture and Urban Design.

García Peralta, B. (1986). La lógica de las grandes acciones inmobiliarias en la ciudad de Querétaro. Estudios Demográficos y Urbanos, 1(3), 375-397. Recuperado de http://estudiosdemograficosyurbanos.colmex.mx/index.php/edu/article/ view/601/594

Glasze, G. (2003). Private neighbourhoods as club economies and shareholder democracies. BelGeo, 1, 87-98. Recuperado de https://journals.openedition.org/ belgeo/15317

Gobierno del Estado de Tamaulipas (2009). Atlas de riesgos de los municipios de Tampico, Madero y Altamira del Estado de Tamaulipas. Ciudad Victoria, Tamps.: Gobierno del Estado de Tamaulipas.

Harvey, D. (1990). La condición de la posmodernidad. Investigación sobre los orígenes del cambio cultural. Ciudad de México: Amorrortu.

Hidalgo, R. (2004). De los pequeños condominios a la ciudad vallada: las urbanizaciones cerradas y la nueva geografía social en Santiago de Chile (1990-2000). Revista Latinoamericana de Estudios Urbano Regionales, 30(91), 29-52. Recuperado de http://www.eure.cl/index.php/eure/article/view/1277 
Hidalgo, R. y Borsdorf, A. (2005). Megaproyectos residenciales vallados en la periferia: ¿barrios cerrados autosuficientes o nuevas ciudades? Urbano, 8(12), 5-12. Recuperado de http://www.redalyc.org/articulo.oa?id=19801204

Hurtado Baker, S. J. (2014). El Gran Humedal de la planicie del Río Tamesí. Región de la desembocadura del Río Pánuco. Trabajo presentado en el $4^{\circ}$ Congreso de Investigación en Cambio Climático. Universidad Autónoma de Tamaulipas. México. Recuperado de http://www.pincc.unam.mx/4tocongreso/sedes_html/ TAMAULIPAS\%204CNICC2014/susana_hurtado_baker.pdf

Ickx, W. (2002). Los fraccionamientos cerrados en la Zona Metropolitana de Guadalajara. En F. Cabrales-Barajas (Comp.), Latinoamérica: países abiertos, ciudades cerradas (pp. 117-144). Guadalajara: Universidad de Guadalajara / UNESCO.

Janoschka, M. (2003). Nordelta, ciudad cerrada. El análisis de un nuevo estilo de vida en el Gran Buenos Aires. Revista Electrónica de Geografia y Ciencias Sociales, 7(146), 26-30. Recuperado de http://www.ub.edu/geocrit/sn/sn-146 (121).htm

Juárez Martínez, M. L. (2006). Segregación urbana y sus implicaciones en las ciudades. Una aproximación teórica. Palapa. Revista de Investigación Científica en Arquitectura, 1(2), 45-50. Recuperado de http://www.redalyc.org/pdf/948/ 94810207.pdf

Juárez Martínez, M. L. (2007). Fraccionamientos cerrados, entre la segregación y la integración urbana en una ciudad media. El caso de Colima-Villa de Álvarez 1980-2005 (Tesis de maestría, Universidad de Colima, Facultad de Arquitectura). Recuperado de http://digeset.ucol.mx/tesis_posgrado/Pdf/Ma_Liliana_Juarez_ Martinez.pdf

Ley para el Desarrollo Urbano del Estado de Tamaulipas (2006). Periódico Oficial del Estado de Tamaulipas, 25 de abril.

Lynch, K. (1960). La imagen de la ciudad. Cambridge, Massachusetts y Londres: Institute of Technology, Joint Center for Urban Studies.

McGarigal, K., Tagil, S. y Cushman, S. A. (2009). Surface metrics: An alternative to patch metrics for the quantification of landscape structure. Landscape Ecology, 24(3), 433-450. Recuperado de https://link.springer.com/article/10.1007/s10980009-9327-y

McKenzie, E. (1994). Privatopia: Homeowner associations and the rise of residential private government. New Haven y Londres: Yale University Press.

Méndez Sáinz, E. y Rodríguez Chumillas, I. (2005). Comunidades cercadas en la frontera México-Estados Unidos. Scripta Nova. Revista Electrónica de Geografía y Ciencias Sociales, 8(171). Recuperado de http://www.ub.edu/geocrit/sn/ sn-171.htm

Mendoza Terrazas, C. y Sánchez Flores, E. (2009). Crecimiento urbano disperso en la frontera norte de México. Organización espacial y eficiencia de los patrones de crecimiento urbano en Ciudad Juárez, Chihuahua. Trabajo presentado en el $\mathrm{V}$ Congreso Internacional Ciudad y Territorio Virtual "Estrategias de transfor- 
mación y gestión de la ciudad: perspectivas y nuevas tecnologías". Barcelona. Recuperado de https:/upcommons.upc.edu/handle/2099/11347

Pierluigi, N. (1992). Periferia. Metrópoli. Erranza. UR: Urbanismo Revista, 9-10, 8-14. Recuperado de https://upcommons.upc.edu/handle/2099/3273

Prévôt Schapira, M. F. (2000). Segregación, fragmentación, secesión. Hacia una nueva geografía social en la aglomeración de Buenos Aires. Economía, Sociedad y Territorio, 2(7), 405-431. Recuperado de http://www.redalyc.org/articulo. oa? id $=11100702$

Programa Metropolitano de Ordenamiento Territorial de Altamira, Ciudad Madero y Tampico (POT) (2010). Tamaulipas: Instituto Metropolitano de Planeación del Sur de Tamaulipas (Imeplan). Recuperado de http://www.imeplansurdetamaulipas.gob.mx/plan\%20y\%20pro.htm

Programa Metropolitano de Ordenamiento Territorial de Altamira, Ciudad Madero y Tampico (POT) (2010a). Mapa de subcuencas, Zona Metropolitana de Tampico, plano clave ME-6. México: Programa Metropolitano de Ordenamiento Territorial de Altamira, Ciudad Madero y Tampico. Recuperado de http://www. imeplansurdetamaulipas.gob.mx/JPGs\%20POT/Metropolitano/Estrategia/ ME-6\%20Cuencas\%20Metropolitanas\%20-90x1250-2.jpg

Puebla Cadena, C. (2002). Del intervencionismo estatal a las estrategias facilitadoras: los cambios en la política de vivienda en México, 1972-1994. Ciudad de México: El Colegio de México, A.C.

Pulido, N. (2014). Bordes urbanos metropolitanos en Venezuela ante nuevas leyes y proyectos inmobiliarios. Cuadernos de Geografía. Revista Colombiana de Geografia, 23(1), 15-38. Recuperado de http://www.redalyc.org/articulo. oa? id=281829103001

Ramírez Velázquez, B. R. (2007). Del suburbio y la periferia al borde: el modelo de crecimiento de la Zona Metropolitana del Valle de México (ZMVM). L'Ordinaire des Amériques, 207, 69-89. Recuperado de https://journals.openedition.org/ orda/3350

Rodríguez, J. y Arriagada, C. (2004). Segregación residencial en la ciudad latinoamericana. Eure, 30(89), 5-24. Recuperado de http://www.redalyc.org/articulo. oa? id=19608901

Roitman B., S. (2004). Urbanizaciones cerradas: estado de la cuestión hoy y propuesta teórica. Revista de Geografia Norte Grande, 32, 5-19. Recuperado de http:// www.redalyc.org/pdf/300/30003201.pdf

Ruiz López, C. F., Alvarado Rosas, C. y Coronado Amaro, F. (2015). Dinámicas territoriales y fraccionamientos cerrados en la Zona Metropolitana de Cuernavaca. $20^{\circ}$ Encuentro Nacional sobre Desarrollo Regional en México, AMECIDER / UNAM, Cuernavaca, Morelos, 17 a 20 de noviembre.

Svampa, M. (2001). Los que ganaron. La vida en los countries y barrios privados. Buenos Aires: Biblos. 
Vidal-Koppmann, S. (2014). Countries y barrios cerrados. Mutaciones socioterritoriales de la región metropolitana de Buenos Aires. Buenos Aires: Dunken.

Webster, Ch., Glasze, G. y Frantz, K. (eds.) (2004). Private cities global and local perspectives. Nueva York: Routledge.

\section{Acerca de las autoras}

Judith del Carmen Garcés Carrillo es doctora en Arquitectura por la Universidad Autónoma de Tamaulipas (UAT), México. Es profesora de la carrera de Arquitectura e investigadora del Cuerpo Académico de Urbanismo y Medio Ambiente de la Facultad de Arquitectura, Diseño y Urbanismo de la UAT. Sus líneas de investigación son: expansión urbana, ordenamiento territorial y urbanismo cerrado. Entre sus publicaciones se encuentra: Garcés, J. C. y Fuentes Pérez, C. A. (2015). Efectos de vecindad debido a urbanizaciones residenciales cerradas en Tamaulipas, México. Legado de Arquitectura y Diseño, 17, 125-138.

Mireya Alicia Rosas Lusett es doctora en Ámbitos de la Investigación de la Energía y el Medio Ambiente por la Universidad Politécnica de Cataluña (UPC). Es investigadora líder del Cuerpo Académico de Urbanismo y Medio Ambiente de la Facultad de Arquitectura, Diseño y Urbanismo de la Universidad Autónoma de Tamaulipas (UAT), donde también es profesora de licenciatura y posgrado. Obtuvo el reconocimiento Cum Laude, por la UPC, y el Premio Investigación de Excelencia en 2012 y 2014, por la UAT. Sus líneas de investigación son: sostenibilidad urbana y confort en espacios exteriores. Es profesora de carrera y posgrado en la Facultad de Arquitectura, Diseño y Urbanismo de la Universidad Autónoma de Tamaulipas. Entre sus publicaciones se encuentra: Rosas-Lusett, M., Bartorila, M. y Ocon, S. (2016). Laguna del Carpintero, regulador climático en el área urbana de Tampico, México. Legado de Arquitectura y Diseño, 20, 113-123.

Fecha de recepción: 30 de agosto de 2017.

Fecha de aceptación: 10 de enero de 2018. 
